\title{
Effect of Insulin Receptor-Knockdown on the Expression Levels of Blood-Brain Barrier Functional Proteins in Human Brain Microvascular Endothelial Cells
}

\author{
Hinako Nagano' • Shingo Itol,2 • Takeshi Masuda ${ }^{1,2}$ • Sumio Ohtsukil,2 (D)
}

Received: 20 July 2021 / Accepted: 20 October 2021 / Published online: 22 November 2021

(c) The Author(s), under exclusive licence to Springer Science+Business Media, LLC, part of Springer Nature 2021

\begin{abstract}
Purpose The insulin receptor (INSR) mediates insulin signaling to modulate cellular functions. Although INSR is expressed at the blood-brain barrier (BBB), its role in the modulation of BBB function is poorly understood. Therefore, in this study, we aimed to analyze the effect of INSR knockdown on the expression levels of functional proteins at the BBB.

Methods We established the INSR-knockdown cell line (shINSR) using human cerebral microvascular endothelial cells (hCMEC/D3). The cellular proteome was analyzed using quantitative proteomics.

Results INSR mRNA and protein expressions were decreased in shINSR cells. The suppression of INSRmediated signaling in shINSR cells was evaluated. The proteins involved in glycolysis and glycogenolysis were suppressed in shINSR cells. As amyloid- $\beta$ peptide-related proteins, the expressions of presenilin-1 was increased, and those of the insulin-degrading enzyme and neprilysin were decreased. The expressions of BBB transporters, including the ABCB1/MDR1, ABCG2/BCRP, and
\end{abstract}

Supplementary Information The online version contains supplementary material available at https://doi.org/10. 1007/s11095-021-03131-8.

Sumio Ohtsuki

sohtsuki@kumamoto-u.ac.jp

1 Department of Pharmaceutical Microbiology, School of Pharmacy, Kumamoto University, 5-1 Oe-honmachi, Chuo-ku, Kumamoto 862-0973, Japan

2 Department of Pharmaceutical Microbiology, Faculty of Life Sciences, Kumamoto University, 5-1 Oe-honmachi, Chuo-ku, Kumamoto 862-0973, Japan
SLCO2A1/OATP2A1 were significantly decreased by more than $50 \%$ in shINSR cells. The efflux activity of ABCB1/MDR1 was also suppressed. The expressions of the low-density lipoprotein receptor-related protein 1 were significantly increased, and those of the transferrin receptor were significantly decreased in shINSR cells. The expression of claudin-5 was also suppressed in shINSR cells.

Conclusions The present study suggests that INSR-mediated signaling is involved in the regulation of functional protein expression at the $\mathrm{BBB}$ and contributes to the maintenance of BBB function. Changes in the expressions of amyloid- $\beta$ peptide-related proteins may contribute to the development of cerebral amyloid angiopathy via the suppression of INSR-mediated signaling.

KEYWORDS Brain microvascular endothelial cells . Blood-brain barrier - Insulin receptor - Transporter . Proteomics

\section{INTRODUCTION}

The blood-brain barrier (BBB) is a critical interface that regulates the exchange between the blood and brain. It consists of brain microvascular endothelial cells (BMECs), along with pericytes, astrocytes, neurons, and the extracellular matrix as neurovascular units [1]. Importantly, tight junctions between BMECs restrict paracellular diffusion of substances between the blood and brain, and various transporters mediate the selective uptake of substances essential for brain functions. In addition, transporters responsible for brain-to-blood efflux transport also function at the BBB [2]. BBB dysfunction is associated 
with neurodegenerative diseases, such as Parkinson's and Alzheimer's diseases (AD), as well as various central nervous system (CNS) diseases, including stroke, multiple sclerosis, and brain tumors [3-7]. BBB dysfunction has also been reported in systemic diseases such as diabetes and hypertension [8]. Epidemiological studies have indicated that type 2 diabetes is a risk factor for $\mathrm{AD}$ [9-11]. Chemically-induced type 1 diabetes reportedly enhanced amyloid- $\beta$ peptide accumulation and tau phosphorylation in the brain of AD model mice [13]. These findings indicate the possibility that the modulation of BBB function by blood-related conditions may affect the progression of $\mathrm{AD}$ by changing the brain homeostasis.

Insulin is a molecule associated with diabetes and $\operatorname{AD}[13,14]$. Insulin activates the phosphorylation signaling in a number of molecules, including extracellular signal-regulated kinase (ERK) and protein kinase $B$, via the insulin receptor (INSR), which is expressed at the BBB [15]. Therefore, insulin is expected to be a key modulator of BBB function, connecting various CNS and systemic diseases. High-insulin and high-glucose treatments weakened tight junctions in human BCECs in vitro [16]. The mRNA levels of the ABCB1/ MDR1, which is a major BBB efflux transporter, was also suppressed by high-insulin treatment in cultured human BMECs [17]. High-fat diet (HFD)-fed mice show increased serum insulin levels, while the expression levels of transporters (Slc2a1/Glut1 and Abcbla/Mdrla) and tight junction proteins (claudin- 5 and occludin) decrease in the isolated brain microvessels of HFD-fed mice [18]. The efflux function of Abcbla/Mdrla at the $\mathrm{BBB}$ is also decreased in the HFD-fed mice. In a rat model of streptozotocin (STZ)-induced type 1 diabetes, the protein expression and function of Abcbla/Mdrla were decreased at the BBB, which were later restored by insulin treatment [19]. These reports suggest that insulin is involved in the regulation of BBB function.

INSR is expressed at the BBB and transports insulin from the circulating blood to the brain via transcytosis [20, 21]. Many studies have focused on the receptormediated transcytosis ability to enable efficient drug delivery to the brain with anti-INSR antibodies [22-24]. In contrast, data on INSR-mediated regulation of BBB function are limited. A study using endothelial cell-specific INSR knockout mice reported increased distribution of dextran to the olfactory bulb and median eminence, and decreased expression of zonula occludens-1 (ZO-1) in the hypothalamus [25]. Our previous study with HFD-fed mice indicated the possibility that modulation of insulin signaling changes not only tight junctions but also transport functions [18].

Therefore, the purpose of the present study was to clarify the role of INSR-mediated signaling in the regulation of protein expression and function at the BBB using INSR-knockdown human BMECs (hCMEC/D3). Protein expression levels were comprehensively analyzed via quantitative proteomics in the INSR-knockdown hCMEC/D3 cells. Furthermore, changes in the expression levels of transporter and receptor proteins were evaluated by targeted proteomics, and functional changes in ABCB1/MDR1 were examined in the INSR-knockdown human BMECs by calcein accumulation assay.

\section{MATERIALS AND METHODS}

\section{Cell Culture}

hCMEC/D3 cells are the immortalized human cerebral microvascular endothelial cells [26]. hCMEC/ D3 cells were cultured in endothelial cell growth basal medium-2 (EBM-2; Lonza, Walkersville, MD, USA) on collagen type I-coated dishes in an atmosphere of $95 \%$ air and $5 \%$ carbon dioxide $\left(\mathrm{CO}_{2}\right)$ at $37{ }^{\circ} \mathrm{C}$. EBM-2 was supplemented with $5 \%$ fetal bovine serum (FBS) (Nichirei Bioscience, Tokyo, Japan), $1 \%$ penicillin-streptomycin (FUJIFILM Wako Pure Chemical, Osaka, Japan), $1.4 \mu \mathrm{M}$ hydrocortisone (Sigma-Aldrich, St. Louis, MO, USA), $5 \mu \mathrm{g} / \mathrm{mL}$ ascorbic acid (FUJIFILM Wako Pure Chemical), $10 \mathrm{mM}$ lithium chloride (FUJIFILM Wako Pure Chemical), $1 \%$ chemically-defined lipid concentrate (Gibco/ Invitrogen, Carlsbad, CA, USA), $1 \mathrm{ng} / \mathrm{mL}$ human basic fibroblast growth factor (Sigma-Aldrich), and $10 \mathrm{mM}$ 2-[4-(2-hydroxyethyl)piperazin-1-yl] ethanesulfonic acid (HEPES; Sigma-Aldrich). The medium was changed 2-3 times per week after seeding.

For insulin treatment, $1 \times 10^{5}$ cells were seeded in a 6-well plate and cultured to $80 \%$ confluence. The medium was replaced with EBM-2 containing no additional factors and cultured for $24 \mathrm{~h}$ to nullify the effect of insulin in FBS and achieve 100\% confluency. Insulin (FUJIFILM Wako Pure Chemical) was added to achieve a final concentration of $10 \mathrm{nM}$ and incubated for $5 \mathrm{~min}$. This condition induces ERK phosphorylation in hCMEC/D3 cells [16]. The insulinfree group was incubated with EBM-2 containing no additional factors. After washing the cell surface with cold phosphate-buffered saline (PBS), the cells were collected and snap-frozen in liquid nitrogen. 


\section{INSR-Knockdown with Short Hairpin RNA (shRNA)}

The INSR-knockdown hCMEC/D3 cells (shINSR) were established by stably transfecting the cells with INSR-targeted shRNA in the pLKO.1 vector (TRCN0000196786; Sigma-Aldrich). Control hCMEC/D3 cells (shNT) were prepared by transfection with non-targeted scrambled shRNA in pLKO.1 vector (MISSION pLKO.1-puro Non-Target shRNA Control Transduction Particles (SHC016V-1EA); Sigma-Aldrich). hCMEC/D3 cells were seeded at a density of $0.5 \times 10^{5}$ cells in 24-well collagen type I-coated plates (Corning, Corning, NY, USA) and cultured for 1 day. Before transduction, the medium was replaced with $1 \mathrm{~mL}$ of EBM-2 culture medium containing $8 \mathrm{mg} / \mathrm{mL}$ hexadimethirine bromide. Lentivirus containing INSR-targeted shRNA in the pLKO. 1 vector or non-targeted shRNA was added to the medium at a multiplicity of infection (MOI) of 3. Twenty-four hours after transduction, cells were passaged to a $100 \mathrm{~mm}$ collagen type I-coated culture dish (Corning) and selected in EBM-2 culture medium supplemented with $2 \mu \mathrm{g} / \mathrm{mL}$ puromycin for 2 weeks. Then, selected cells were cultured in EBM-2 culture medium supplemented with $2 \mu \mathrm{g} / \mathrm{mL}$ puromycin for further analysis.

\section{Quantitative Real-Time Polymerase Chain Reaction (PCR)}

Total RNA was isolated using the RNeasy kit (Qiagen, Valencia, CA, USA), and cDNA was prepared from $50 \mathrm{ng}$ total RNA using ReverTraAce (Toyobo, Osaka, Japan) and an oligo dT primer. Real-time PCR was conducted with QuantStudio 3 (Applied Biosystems, Foster City, CA, USA) using a Prime Time qPCR assay (Integrated DNA Technologies, Coralville, IA, USA). The following primers: primer 1, 5'-CTGGATCAA CCCGACAACTG-3'; primer 2, 5'-GGTTGACAATCT CCAGGAAGG-3'; and probe, 5'-/56-FAM/AGAGAG TCA/ZEN/CTGACCTCATGCGC/3IABkFQ/-3' were designed for INSR. Meanwhile, the following primers: primer 1, 5'-ACATCGCTCAGACACCATG-3'; primer 2, 5'-TGTAGTTGAGGTCAATGAAGGG-3'; and probe, 5'-/56-FAM/AAGGTCGGA/ZEN/GTCAACGGA TTTGGTC/3IABkFQ/-3' were designed for glyceraldehyde 3-phosphate dehydrogenase (GAPDH). Synthetic DNA from INSR or GAPDH gene was used for calibration curves, and INSR mRNA levels were normalized to those of GAPDH in the same sample.

\section{Western Blotting Analysis}

Whole lysates of hCMEC/D3 cells treated with insulin were separated using $12 \%$ sodium dodecyl sulphate-polyacrylamide gel and blotted onto a polyvinylidene fluoride membrane (Bio-Rad, Hercules, CA, USA). The membrane was blocked with Blocking One-P (Nacalai Tesque, Kyoto, Japan) and immunoblotted with primary antibodies overnight at $4{ }^{\circ} \mathrm{C}$. The following primary antibodies were used: phospho-p44/42 MAPK (phospho-ERK1/2), 1/2000 dilution (4370S; Cell Signaling Technology, Danvers, MA, USA); p44/42 MAPK (ERK1/2), 1/1000 dilution (4695S; Cell Signaling Technology), and $\beta$-actin, 1/5000 (12262S; Cell Signaling Technology). The membrane was incubated with horseradish peroxidase (HRP)-conjugated secondary anti-rabbit IgG antibody (7074S; Cell Signaling Technology) and then imaged with a Western BLoT Hyper HRP substrate (Takara Bio, Shiga, Japan) using an Omega Lum G imaging system (Gel Company, San Francisco, CA, USA). The membrane was first reacted with an antibody against phospho-ERK1/2. After imaging, the first and secondary antibodies were stripped from the membrane using EzReprobe reagent (ATTO, Tokyo, Japan). Next, the membrane was blocked with Blocking One-P and reprobed with an antibody against ERK1 $/ 2$. $\beta$-actin was detected by reprobing after detection of ERK1/2. Band intensities were obtained using Image J software v.1.52a (National Institutes of Health, Bethesda, MD, USA).

To detect claudin-5, whole lysates of hCMEC/D3 cells were separated using SuperSep TMAce, 10-20\% (FUJIFILM Wako Pure Chemical). The membrane was cut into two pieces between 20 and $35 \mathrm{kDa}$ and blocked with $5 \% \mathrm{w} / \mathrm{v}$ skimmed milk in Tris-buffered saline containing $0.1 \%$ Tween 20 . The lower membrane was immunoblotted with primary antibody against claudin-5, 1:1000 dilution (35-2500, Invitrogen, Carlsbad, CA, USA), whereas and the upper membrane was immunoblotted with the HRP-conjugated antibody against $\beta$-actin, 1/10000 (12262S; Cell Signaling Technology). The lower membrane was incubated with HRP-conjugated secondary anti-mouse IgG antibody (7076S; Cell Signaling Technology) and imaged as described above.

\section{Subcellular Fractionation of hCMEC/D3 Cells}

The cytosol, crude membrane, and plasma membrane fractions were prepared from $10 \mathrm{~cm}$ dishes $(80 \%$ confluent) $\times 4$ dishes of hCMEC/D3 cells using a Membrane Protein Extraction Kit (BioVision, Milpitas, CA, USA) according to a previous report [27]. Protein concentrations of the fractionated samples were measured using 
a BCA protein assay kit (Thermo Fisher Scientific, Waltham, MA, USA).

\section{Sequential Windowed Acquisition Of All Theoretical Fragment Ion-Mass Spectra (SWATH-MS)-Based Quantitative Proteomics}

Subcellular fractions of hCMEC/D3 cell were digested by the phase-transfer surfactant method, as previously described [28, 29]. Briefly, the protein samples $(5 \mu \mathrm{g})$ were solubilized in $12 \mathrm{mM}$ sodium deoxycholate and $12 \mathrm{mM}$ N-lauroylsarcosinate in $100 \mathrm{mM}$ Tris-HCl $(\mathrm{pH}$ 9.0), and denatured at $95{ }^{\circ} \mathrm{C}$ for $5 \mathrm{~min}$. After sonication, reductive alkylation was conducted with $100 \mathrm{mM}$ dithiothreitol and $550 \mathrm{mM}$ iodoacetamide in $50 \mathrm{mM}$ ammonium bicarbonate. After fivefold dilution, the samples were digested with lysyl endopeptidase (FUJIFILM Wako Pure Chemical) for $3 \mathrm{~h}$ and with trypsin (Promega, Madison, WI, USA) for $16 \mathrm{~h}$. The detergents were removed by ethyl acetate under acidic conditions. After drying by vacuum centrifugation, the digested samples were dissolved in $5 \%$ acetonitrile $/ 0.1 \%$ trifluoroacetic acid and desalted using GL-Tip SDB and GC (GL Sciences, Tokyo, Japan). The sample was reconstituted with $0.1 \%$ trifluoroacetic acid after drying, and subjected to liquid chromatography-tandem mass spectrometry (LC-MS/MS). The samples were analyzed by SWATHMS on TripleTOF5600 (SCIEX, Framingham, MA, USA) interfaced with a DIONEX Ultimate 3000 RSLC nano system (Thermo Fisher Scientific). Proteins were identified by Protein Pilot v.4.5 (SCIEX) with MS data from information-dependent acquisition (IDA) using the UniProt Human Proteome database. Peptide peaks were analyzed with SWATH data using PeakView Software v.2.1 (SCIEX) or by DIA-NN v.1.7.14 [30] with a spectral library constructed from the identification data from IDA. PeakView software was used for the analysis of transporters and receptors in the plasma membrane fraction, as shown in Table 2. The protein expression levels were calculated as the protein peak areas by summing the peak areas of the unique peptides. The same peptides were used to calculate the protein peak areas in both shNT and shINSR samples. In all other analyses, the DIA-NN data were used. The analysis of INSR shown in Fig. S1 was conducted using DIA-NN with an in-house spectral library covering the whole human proteome. Protein expression data were calculated from precursor peak area data using the MaxLFQ algorithm integrated in DIA-NN [31]. The values of all quantified proteins are listed in Table S1. Pathway analysis was conducted using the Kyoto Encyclopedia of Genes and Genomes (KEGG) [32].

\section{Protein Quantification by Targeted Proteomics}

To prepare the internal standard peptides for targeted proteomics, artificial protein concatenating internal standard peptides were synthesized from cDNA using Musaiboukun (Taiyo Nippon Sanso, Tokyo, Japan) in the presence of stable isotope-labeled lysine and arginine (Taiyo Nippon Sanso) [33]. The internal standard peptides were produced from artificial proteins by trypsin digestion. The plasma membrane fraction of hCMEC/D3 cells was digested with trypsin as described in the quantitative proteomic analysis. After trypsin digestion, stable isotope-labeled internal standard peptides were spiked to the samples. Detergents were then removed, and desalting was performed as described above. The prepared peptide samples were analyzed using a micro-LC system (Ekisigent, Redwood City, CA, USA) connected to a triple quadrupole mass spectrometer (QTRAP6500, SCIEX). The analysis was performed according to previous studies [34, 35]. Briefly, the protein expression levels were quantified by the detection of unique peptides for each target protein with multiple reaction monitoring (MRM). The product ion peaks from each target peptide were extracted from the MRM data using the Skyline software [36]. The peak area ratio of the target peptide to the internal standard peptide was calculated, and the protein expression levels were determined as the average values of the peaks area ratios from three or four product ions.

\section{In vitro ABCB I/MDR I Functional Analysis}

ABCB1/MDR1 function was analyzed using a multidrug resistance assay kit (Calcein AM) (Cayman Chemical, Ann Arbor, MI, USA) according to the manufacturer's protocol. We used a cell-based assay with verapamil and cyclosporin A in the kit as inhibitors of MDR1. The hCMEC/D3 cells $\left(2.0 \times 10^{4}\right.$ cells per well) were seeded onto 96 -well plates, collagen type I coated black culture plates (Thermo Fisher Scientific), and cultured for $24 \mathrm{~h}$. The medium was aspirated from wells and the cells were treated with the complete EBM-2 medium containing verapamil (1:2000) or cyclosporin A (1:1000), recommended dilution of the kit, for $30 \mathrm{~min}$ in a $\mathrm{CO}_{2}$ incubator. At the end of the treatment, calcein AM solution $(2 \times)$ was added to each well and incubated for an additional $30 \mathrm{~min}$. Then, the cells were washed twice with the ice-cold medium. Fluorescence was measured using an Infinite M1000 plate reader (Tecan, Maennedorf, Switzerland) with excitation and emission wavelengths of $485 \mathrm{~nm}$ and $535 \mathrm{~nm}$, respectively. 


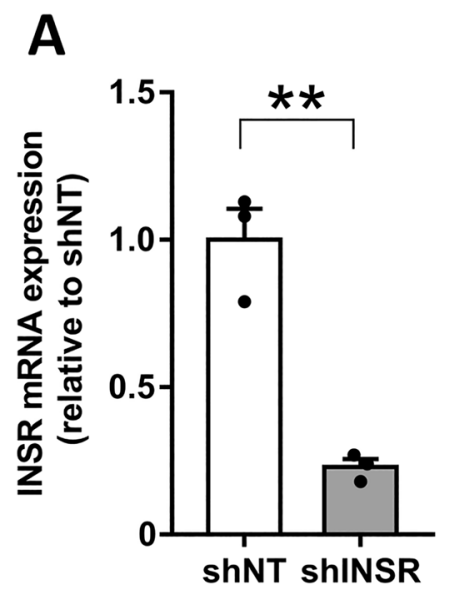

B

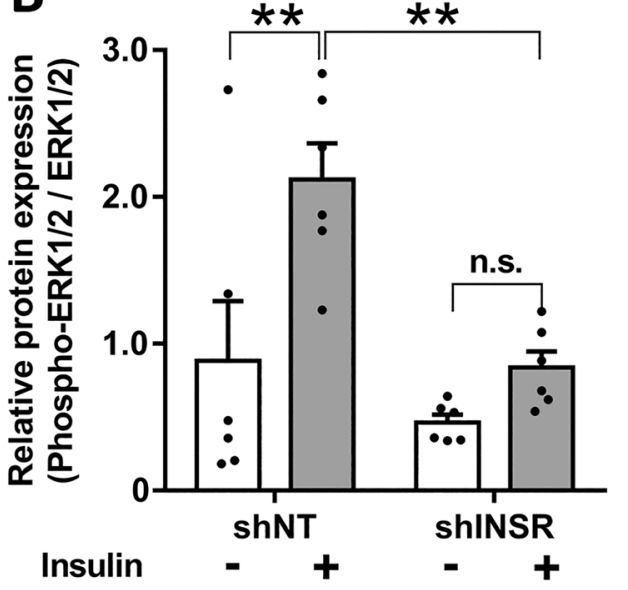

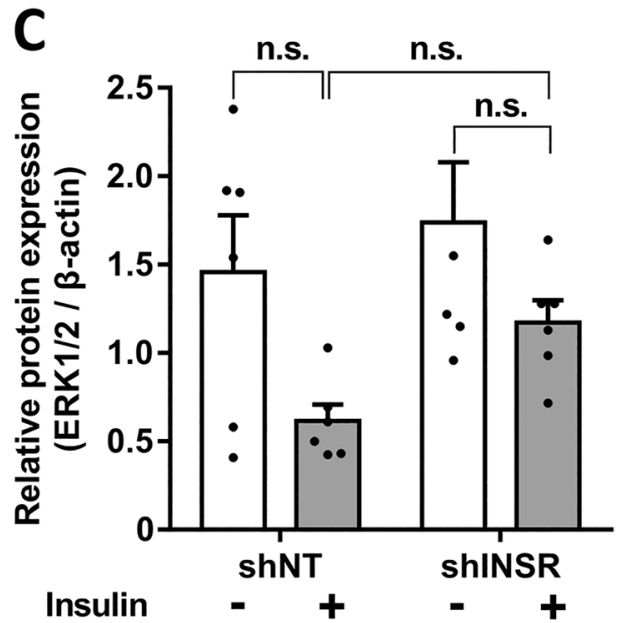

D

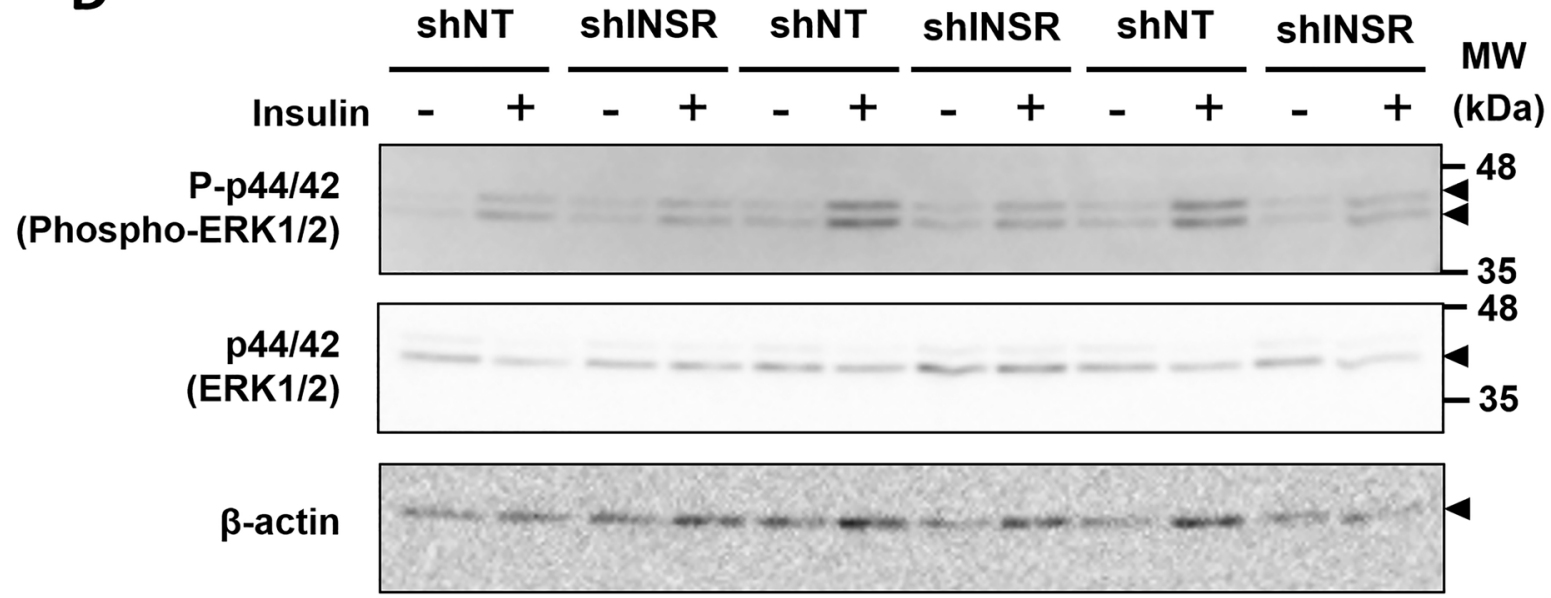

Fig. I Suppression of insulin receptor (INSR) expression and signaling in INSR-knockdown human cerebral microvascular endothelial cells (hCMEC/D3). (A) INSR mRNA expression levels in INSR-knockdown (shINSR) and control (shNT) of hCMEC/D3 cells. Each bar represents the mean $\pm \operatorname{SEM}(n=3$ biological replicates). The dots represent individual data points. (B, $C$ and D) Phosphorylation levels of ERKI/2 by insulin treatment $(10 \mathrm{nM})$. The phosphorylation level is indicated as the ratio of phospho-ERKI/2 to total ERKI/2 (B). The total level of ERK was normalized by $\beta$-actin (C). The representative image of western blot is shown in (D). Each bar represents the mean \pm SEM ( $n=6$ biological replicates). The dots represent individual data points. ${ }^{*} p<0.05, * * p<0.0$ I significantly different. n.s., not significant

The average fluorescence of each sample was calculated from the values measured using a plate reader. The values relative to shNT without inhibitors were then calculated.

\section{Statistical Analysis}

Data are presented as the mean \pm standard error of the mean (SEM). The significant differences between the two groups were estimated using a two-tailed, unpaired Student's t-test by Excel (Microsoft, Redmond, WA, USA). Significant differences among more than two groups were determined by one-way analysis of variance (ANOVA) followed by Tukey's post hoc test using StatMate III v.3.19 (ATMS, Chiba, Japan).

\section{RESULTS}

\section{Suppression of INSR Expression and Signaling in the INSR-Knockdown hCMEC/D3 cells}

hCMEC/D3 cells are immortalized human cerebral microvascular endothelial cells [26]. Our previous proteomic study demonstrated that the protein expression levels of transporters and receptors, including INSR, in hCMEC/D3 cells are similar to those in human brain microvessels [15]. Therefore, INSR-knockdown human BMECs were established by stably introducing INSR-targeted shRNA into hCMEC/D3 cells (shINSR cells). Control cells were developed by introducing non-targeted scrambled shRNA (shNT cells). The suppression of INSR mRNA expression in shINSR cells was examined using qRT-PCR. As shown in Fig. 1A, INSR 
mRNA expression was significantly decreased by $77.0 \%$ in shINSR cells compared to that in shNT cells.

The suppression of INSR protein expression was confirmed using quantitative proteomics. By analyzing the plasma membrane fraction of shNT cells, three tryptic peptides derived from INSR were detected (DLFPNLTVIR, TIDSVTSAQELR and IELQACNQDTPEER [amino acid positions: $101-110,347-358$ and 820-833, respectively]). The amount of these peptides was measured using chromatogram peaks. Chromatograms of the three detected peptides are shown in Fig. S1. Peptide peaks were detected in shNT cells but were below the detection limit in shINSR cells.

To clarify the attenuation of insulin signaling via INSR, the phosphorylation status of ERK1/2 was examined by western blot analysis. The phosphorylation level was calculated as the ratio of phospho-ERK1/2 to ERK1/2. In shNT cells, the phosphorylation level of ERK1/2 significantly increased 2.40-fold after treatment with insulin (10 nM) for 5 min (Fig. 1B and D). In contrast, insulin stimulation did not increase the phosphorylation level of ERK1/2 in shINSR cells. There was no significant induction of ERK1/2 after insulin treatment (Fig. 1C and D). The additional western blot of phospho-ERK1/2 and ERK1/2 performed independently from Fig. 1B-D is shown in Fig. S2. These results indicate that insulin signaling through INSR was suppressed in shINSR cells.

\section{Changes in the Expression of Proteome via INSR Knockdown in hCMEC/D3 Cells}

Changes in protein expression following INSR knockdown were analyzed by SWATH-MS-based quantitative proteomics. Since the target molecules in the present study include membrane transporters and receptors, the cells were fractionated into cytosolic, crude membrane, and plasma membrane fractions to increase the detection sensitivity of the targeted molecules by their concentration in the plasma membrane fraction. As a result, 2938, 3248, and 3030 proteins were identified in the cytosolic, crude membrane, and plasma membrane fractions, respectively (Table 1). Among them, 500 molecules in the cytosolic fraction, 515 molecules in the crude membrane fraction, and 681 molecules in the plasma membrane fraction showed significant changes in shINSR cells by more than 1.50 -fold or less than 0.667 -fold compared to shNT cells.

Insulin modulates glycolysis and glycogen synthesis (glycogenosis) in the liver to regulate blood glucose levels. Hence, the effect of INSR knockdown on the levels of proteins involved in glycolysis and glycogenosis was investigated using proteomic data from shINSR and
Table I Number of identified and changed proteins in the insulin receptor (INSR)-knockdown human cerebral microvascular endothelial cells (hCMEC/D3)

\begin{tabular}{lllll}
\hline & \multicolumn{5}{l}{ Number of proteins } \\
\cline { 2 - 5 } Subcellular fraction & All & $p<0.05^{\mathrm{a}}$ & $\begin{array}{c}>1.5 \text {-fold } \\
(p<0.05)^{\mathrm{b}}\end{array}$ & $\begin{array}{l}<0.667-\text {-fold } \\
(p<0.05)^{\mathrm{c}}\end{array}$ \\
\hline Cytosol & 2938 & 780 & 251 & 249 \\
Crude membrane & 3248 & 1128 & 203 & 312 \\
Plasma membrane & 3030 & 1150 & 322 & 359 \\
\hline
\end{tabular}

The quantified protein values are listed in Table SI. "All" indicates the numbers of proteins identified in all 6 samples of subcellular fractions from INSR-knockdown (shINSR, $n=3$ biological replicates) and control (shNT, $n=3$ biological replicates) of hCMEC/D3 cells. ${ }^{a}$ Number of proteins whose expression was significantly changed $(p<0.05)$ in shINSR cells. ${ }^{b}$ Number of proteins whose expression was significantly changed $(p<0.05)$ by more than 1.50 -fold in shINSR cells. ${ }^{c}$ Number of proteins whose expression was significantly changed $(p<0.05)$ by less than 0.667 -fold in shINSR

shNT cells. As shown in Fig. 2, all glycolytic enzymes, except HKs and GAPDH, were suppressed in shINSR cells. Glycogen synthase (GYS) is not affected by INSR knockdown, while glycogen phosphorylase (PYGL), which produces glucose-1-phosphate from glycogen as glycogenolysis, was significantly suppressed in shINSR cells.

In relation to $\mathrm{AD}$, proteins related to amyloid- $\beta$ peptide $(\mathrm{A} \beta)$, which accumulates in the brain of $\mathrm{AD}$ patients, were also investigated. $A \beta$ was excised from the amyloid precursor protein (APP) by $\beta$-and $\gamma$-secretases. As shown in Fig. 3, APP expression was decreased in shINSR cells, and presenilin-1 (PSEN1), which is a component of $\gamma$-secretase, increased. $\beta$-Secretase was not detected in this analysis. $A \beta$ is degraded by insulindegrading enzyme (IDE) and neprilysisn (membrane metalloendopeptidase, MME) [37, 38]. These proteolytic enzymes were suppressed to $36.0 \%$ and $13.6 \%$ in shINSR cells, respectively. Low-density lipoprotein receptor-related protein 1 (LRP1) is involved in $A \beta$ uptake in BMECs [39], and its expression was only detected in shINSR cells, suggesting its induction by INSR knockdown (Table S1). Given the higher-sensitivity quantification afforded by targeted proteomics shown in the later result, LRP-1 was induced by 2.80 fold in shINSR cells (Fig. 4).

\section{Changes in the Expression Levels Of Transporter and Receptor Proteins via INSR Knockdown in hCMEC/D3 Cells}

The protein expression of ATP-binding cassette (ABC) and solute carrier (SLC) transporters and receptors in plasma membrane fractions from shINSR and shNT 

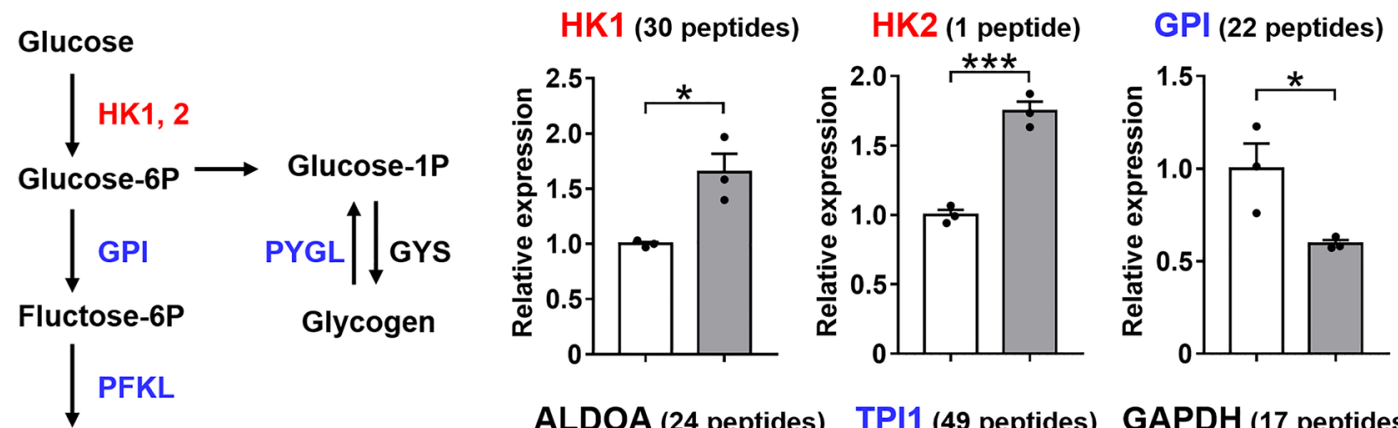

PKFL (3 peptides)

Fluctose-1,6P

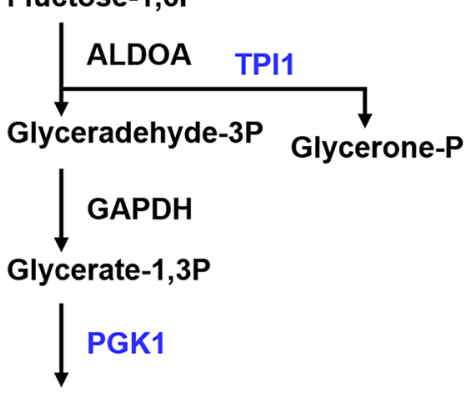

ALDOA (24 peptides
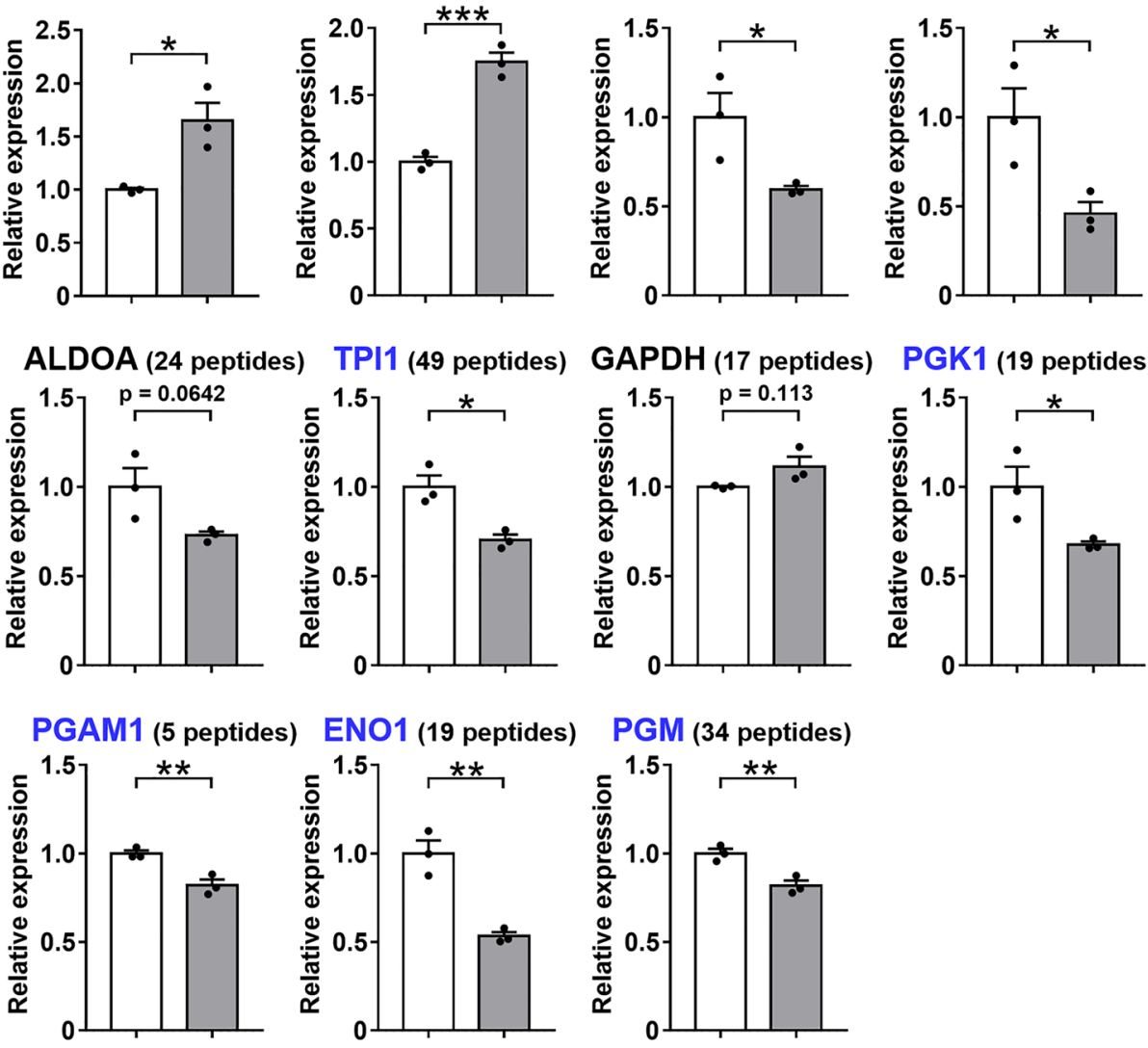

Phosphoenolpyruvate

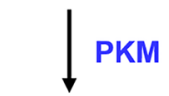

PYGL (10 peptides) GYS (2 peptides)

Pyruvate
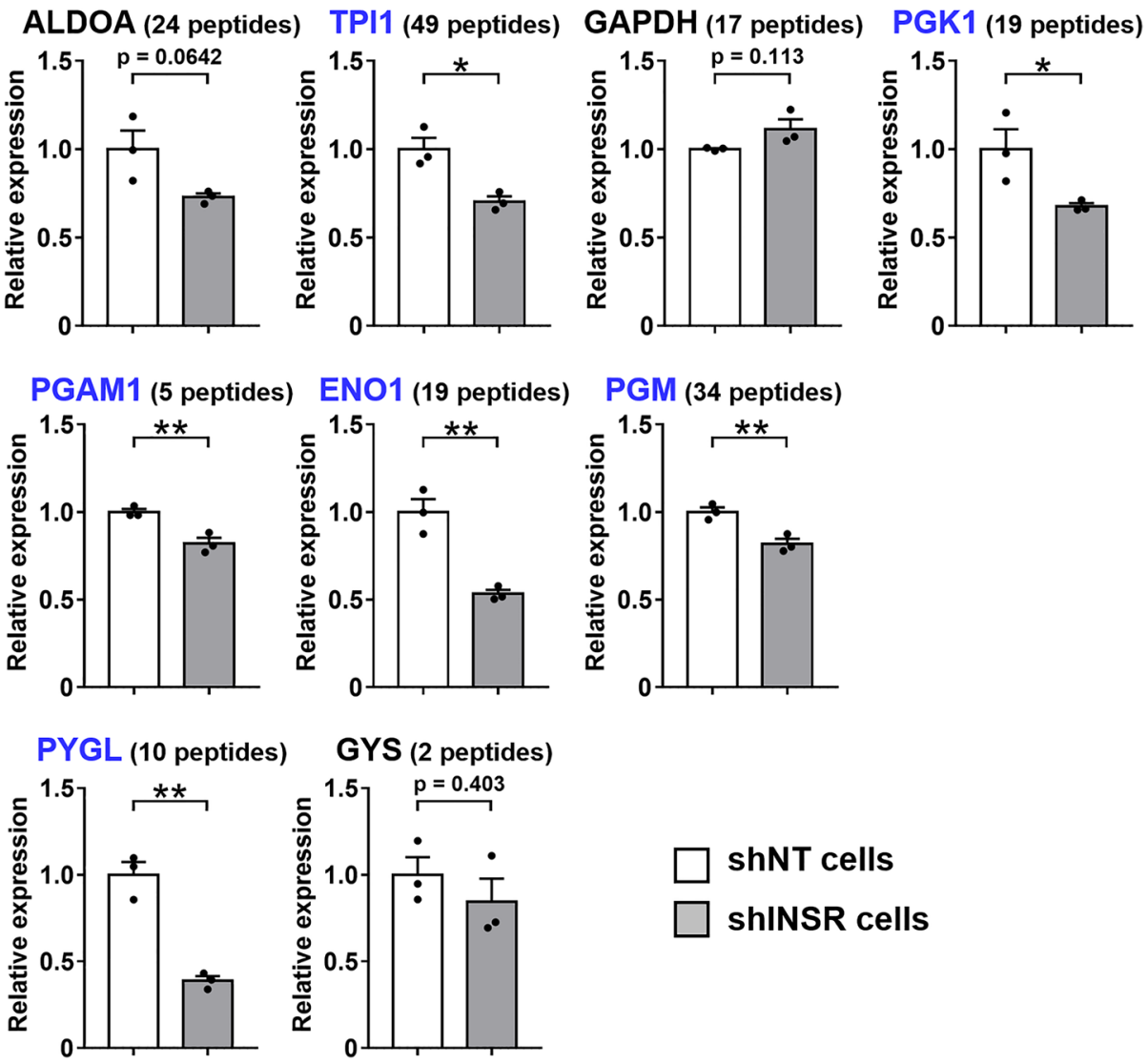

Fig. 2 Expression profiles of enzyme proteins in glycolysis and glycogenosis. Protein expression levels in shINSR cells (closed bars) relative to shNT cells (open bars). Expression levels in the cytosolic fraction were determined using SWATH-MS-based quantitative proteomics. Expression levels of PFKL, PGAMI, and PKM were measured in the crude membrane fraction. Numbers of quantified tryptic peptides for each protein are indicated in parentheses. The enzymes decreased in shINSR cells are colored in blue, and those increased in red. Each bar represents the mean \pm SEM ( $n=3$ biological replicates). The dots represent individual data points. ${ }^{*} p<0.05$, ${ }^{*} p<<0.0$ I, ${ }^{* * *} p<0.00$ I significantly different.

cells was quantified by targeted proteomics with spiking internal standard peptides. This is because targeted proteomics provides more accurate and sensitive quantification than SWATH-based quantitative proteomics and is a suitable method to verify expression data of multiple proteins with high specificity when compared with western blotting [40]. Eighteen transporters showed significant changes in shINSR cells by SWATHMS quantitative proteomics (Table 2; details are shown in Table S2), and 12 of these transporters were selected for quantification by targeted proteomics. Six transporters were excluded from the quantification, because three transporters (SLC17A5, SLC20A2, and SLC12A7) lacked suitable peptides for targeted proteomics, and the other three transporters (SLC15A4, SLC25A4, and ABCD3) are not localized on the plasma membrane. ABCG2/BCRP was not detected by SWATH-based quantitative proteomics, and ABCC4/MRP4 and SLC2A1/ GLUT1 were not significantly different between shINSR and shNT cells, while these transporters were added to the quantification, because they are important transporters for the BBB. As receptors, LRP1 and transferrin receptor (TFRC) were quantified, because they are involved in receptor-mediated transport across the BBB 
A. APP (6 peptides)

B. PSEN1 (3 peptides)

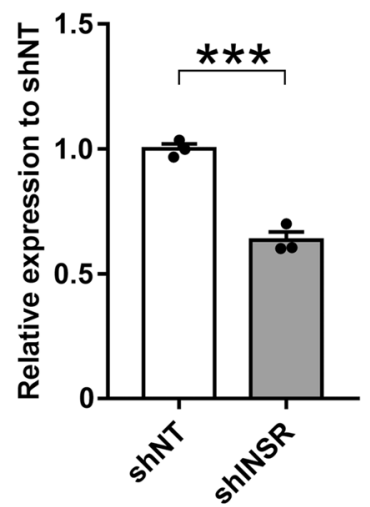

C. IDE (8 peptides)
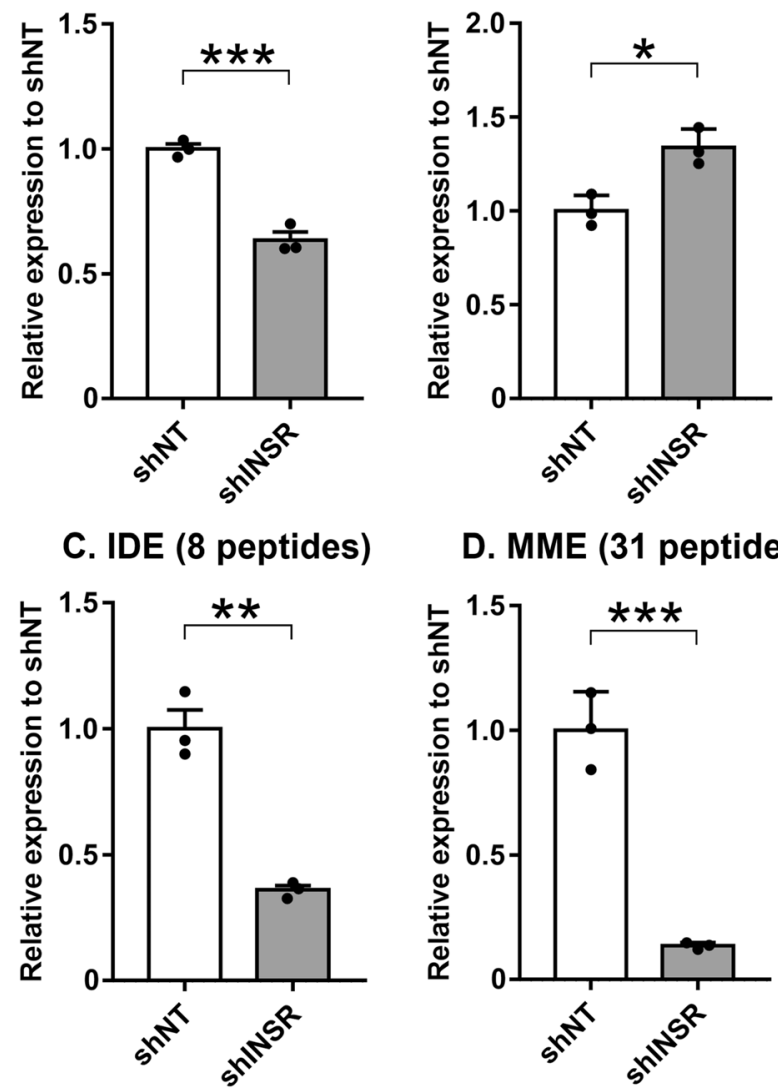

D. MME (31 peptides)

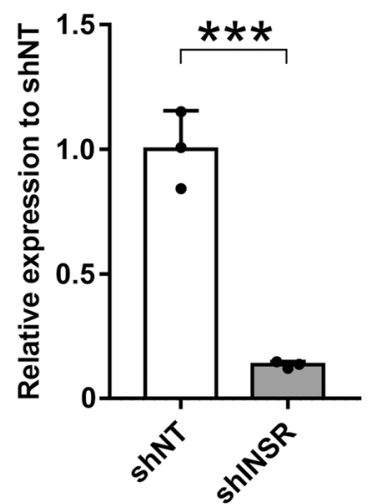

Fig. 3 Expression profiles of amyloid- $\beta$ peptide-related proteins. Protein expression levels in shINSR cells (closed bars) relative to shNT cells (open bars). Expression levels were determined using SWATHMS-based quantitative proteomics. Numbers of quantified tryptic peptides for each protein are indicated in parentheses. Amyloid precursor protein (APP), presenilin (PSENI), and neprilysisn (membrane metalloendopeptidase, MME) were measured in the crude membrane fraction, and insulin-degrading enzyme (IDE) was measured in the cytosolic fraction. Each bar represents the mean $\pm \operatorname{SEM}(n=3$ biological replicates). The dots represent individual data points. $* p<0.05$, $* * 0<0.0$ I, **** $p<0.00$ I significantly different

$[41,42]$, and their protein expression was altered in shINSR cells (Table S2). $\mathrm{Na}^{+} / \mathrm{K}^{+}$-ATPase was quantified as a marker protein for the plasma membrane. Finally, 18 membrane proteins were quantified in the plasma membrane fraction from shINSR and shNT cells by targeted proteomics (Fig. 4).

Quantification by targeted proteomics revealed that nine molecules (ABCB1/MDR1, ABCG2/BCRP, SLCO2A1/OATP2A1, SLC43A3/ENBT1, SLC4A7/ NBC2, SLC12A9/CCC6/CIP1, SLC12A2/NKCC1, LRP1, and TFRC) showed significant changes of more than 1.5 -fold or less than 0.667 -fold in shINSR cells (Fig. 4). ABCB1/MDR1 and ABCG2/BCRP were significantly suppressed by $72.3 \%$ and $58.8 \%$, respectively, in shINSR cells. Among SLC transporters, SLCO2A1/ OATP2A1, a transporter for prostaglandins, decreased
Fold change (shINSR / shNT)

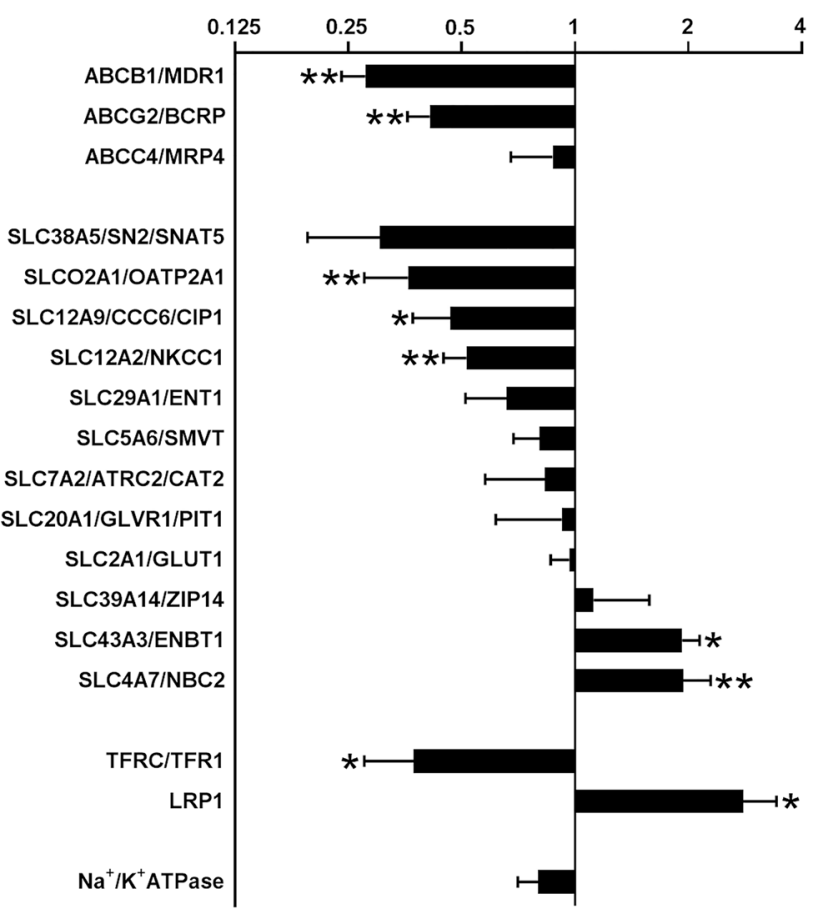

Fig. 4 Changes in the expression levels of transporter and receptor proteins by INSR-knockdown in the plasma membrane fraction of hCMEC/D3 cells. Protein expression was measured by targeted proteomics using standard internal peptides. Fold change was calculated as the ratio of mean protein expression in shINSR cells to shNT cells. Each bar represents the fold of mean \pm error $(n=3$ biological replicates for each cell group). ${ }^{*} p<0.05, * * p<0.01$ significantly different between shINSR and shNT cells. The bar graph indicating individual data points is shown in Fig. S3

Table 2 Number of identified and changed ATP-binding cassette $(A B C)$ and solute carrier (SLC) transporters in the plasma membrane fraction of INSR-knockdown and control of hCMEC/D3 cells

\begin{tabular}{lllllll}
\hline & & \multicolumn{4}{l}{ Number of identified proteins } \\
\cline { 3 - 6 } Subcellular fraction & Family & All & $p<0.05^{\mathrm{a}}$ & $\begin{array}{c}>1.5 \text {-fold } \\
(p<0.05)^{\mathrm{b}}\end{array}$ & $\begin{array}{l}<0.667 \text {-fold } \\
(p<0.05)^{\mathrm{c}}\end{array}$ \\
\hline Plasma membrane & ABC & 9 & 2 & 1 & 1 \\
& SLC & 61 & 22 & 4 & 12
\end{tabular}

"All" indicates the total numbers of ABC or SLC transporter proteins identified in all 6 samples of plasma membrane fractions from both INSR-knockdown (shINSR, $n=3$ biological replicates) and control (shNT, $n=3$ biological replicates) of hCMEC/D3 cells. ABC and SLC transporters were identified by the gene names including "ABC" and "SLC," respectively. ${ }^{a}$ Number of proteins whose expression was significantly changed $(p<0.05)$ in shINSR cells. ${ }^{b}$ Number of proteins whose expression was significantly changed $(p<0.05)$ by more than I.50-fold in shINSR cells. "Number of proteins whose expression was significantly changed $(p<0.05)$ by less than 0.667 -fold in shINSR. The fold changes in each transporter are shown in Table S2

by $64.0 \%$ in shINSR cells. LRP1 expression was significantly induced 2.80-fold, while TFRC significantly decreased by $62.7 \%$. The expression of $\mathrm{Na}^{+} / \mathrm{K}^{+}$ATPase 


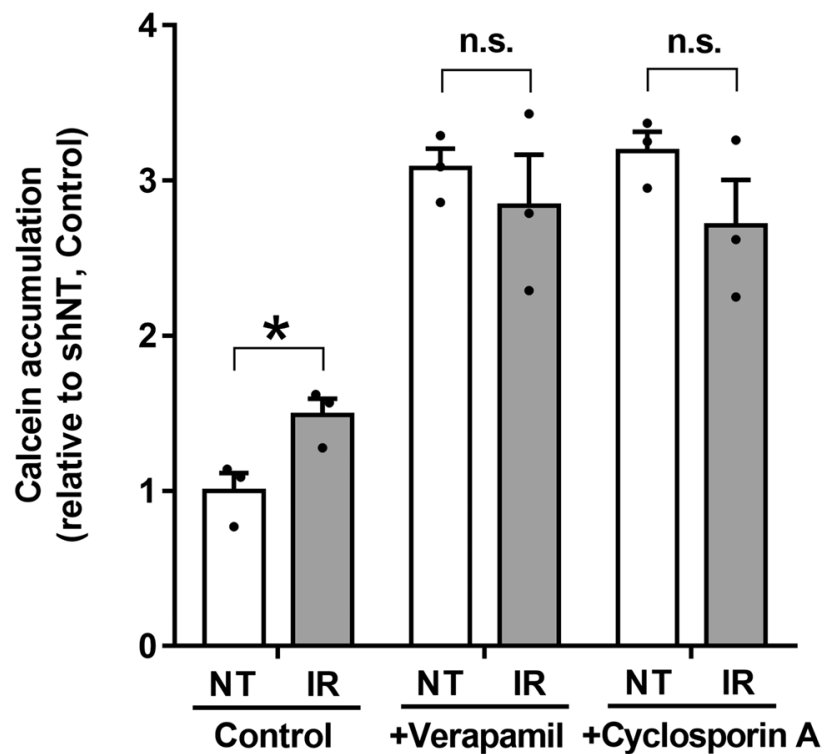

Fig. 5 Effect of INSR-knockdown on the efflux activity of $A B C B I /$ MDRI in hCMEC/D3 cells. The intracellular accumulation of calcein was quantified after pre-incubation with or without verapamil or cyclosporin A in complete endothelial cell growth basal medium-2 (EBM-2) medium. Each bar represents the mean \pm SEM $(n=3$ biological replicates). The dots represent the individual data points. NT, shNT; IR, shINSR cells. $* p<0.05$, significantly different. n.s., not significant

was not significantly different between shINSR and shNT cells $(0.798$-fold, $p=0.132)$, suggesting that the purity of the plasma membrane in the fraction was not significantly different between the cells.

\section{Suppression of ABCB I/MDR I Efflux Function in shINSR Cells}

$\mathrm{ABCB} 1 / \mathrm{MDR} 1$ plays a role in the clearance of exogenous substances from the $\mathrm{BBB}$ and shows the largest suppression in shINSR cells, as shown in Fig. 4. Therefore, we examined the suppression of MDR1 efflux activity in shINSR cells using a calcein accumulation assay. In the calcein-only group, the intracellular accumulation of calcein was significantly increased by 1.49 fold in shINSR cells compared to shNT cells (Fig. 5). When ABCB1/MDR1 activity was inhibited by inhibitors, such as verapamil or cyclosporin A, calcein accumulation was increased and was not significantly different between shINSR and shNT cells. These results suggest that the efflux of calcein by ABCB1/MDR1 was decreased in shINSR cells in accordance with the suppression of its protein expression.

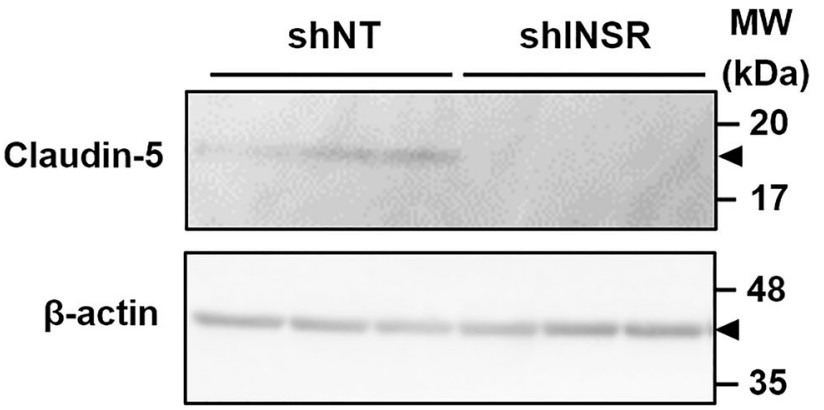

Fig. 6 Protein expression of claudin-5 in shINSR and shNT cells. Western blot analysis was performed using whole-cell lysates of shINSR and shNT cells. The replicates were biological replicates in which the cells were cultured in different wells $(n=3)$

\section{Changes in the Expression Levels of Tight Junction Proteins via INSR Knockdown in hCMEC/D3 Cells}

Tight junctions are an important feature of the BBB. The present SWAH-MS-based quantitative proteomic analysis identified claudin-1, claudin-11, occludin, and ZO-1, known tight junction proteins. Claudin-11 was significantly increased by 1.40 -fold in the crude membrane fraction of shINSR cells, and occludin was increased in crude and plasma membrane fractions of shINSR cells by 2.19- and 2.31-fold, respectively (Table S3). Claudin-5 is the main tight junction protein in the BBB; however, it could not be detected by SWATH-MS-based quantitative proteomics. Therefore, we performed western blot analysis to examine claudin-5 expression. As shown in Fig. 6, the protein expression of claudin-5 was suppressed in shINSR cells when compared with shNT cells.

\section{DISCUSSION}

In shINSR cells, INSR mRNA and protein expression levels were found to be significantly decreased. In addition, the phosphorylation level of ERK1/2 was decreased in shINSR cells, indicating attenuation of insulin signaling via INSR (Fig. 1). Furthermore, the expression levels of proteins involved in glycolysis were altered (Fig. 2). These results suggest that shINSR cells are suitable for studying the effect of INSR-mediated signaling on the protein expression levels in hCMEC/ D3 cells.

Insulin controls blood glucose levels by regulating glucose metabolism in the liver and muscles. In the liver, insulin signaling induces glycolysis and glycogenosis, and both metabolic pathways are suppressed in type 1 diabetes mellitus [43, 44]. In BMECs, the present 
results suggest that the attenuation of insulin signaling suppresses glycolysis and facilitates glycogenosis (Fig. 2). Therefore, insulin regulation partly different from the liver is involved in glucose metabolism in BCECs. The expression levels of SLC2A1/GLUT1 were not changed, while those of HK were induced and of PYGL were suppressed in shINSR cells (Figs. 2 and 4), indicating the possibility that the conversion of glucose taken up in the cells to glycogen was induced in shINSR cells. In the brain, glycogen is mainly stored in astrocytes and is an essential endogenous energy storage during cerebrovascular obstruction [45]. Although glycogen synthesis in BMECs is unknown, the present study suggests that glycogen synthesis is induced in BMECs under insulin-signaling attenuated conditions.

The association between diabetes mellitus in an insulin-resistant state and $\mathrm{AD}$ has been reported [9]. The present study demonstrated that the enzyme producing A $\beta$ from APP increased in shINSRcells, and degrading enzymes decreased (Fig. 3). Despite the decrease in APP, these changes in expression may result in an increase in $\mathrm{A} \beta$ levels in hCMEC/D3 cells following INSR knockdown. In addition to these enzymes, LRP1 is involved in $\mathrm{A} \beta$ uptake in BMECs, from both the brain and blood [39, 46]. MDR1 reportedly mediates efflux transport of $\mathrm{A} \beta$ from BCECs into blood, as cerebral A $\beta$ clearance is mediated by LRP1 $[47,48]$. Changes in expression levels shown in Fig. 4 suggest that INSR knockdown induces $A \beta$ uptake into BMECs via LRP1 induction and attenuates $A \beta$ efflux from BMECs by suppressing MDR1, indicating the possibility of $A \beta$ accumulation in BCECs. Cerebral amyloid angiopathy (CAA) is characterized by $\mathrm{A} \beta$ deposits inside and around brain microvessels. CAA coexists with AD [49], and type 2 diabetes mellitus is a risk factor for CAA [50]. Therefore, we postulate that INSR-mediated regulation of A $\beta$-related proteins contributes to the development of CAA.

The present study also demonstrated a decrease in SLCO2A1/OATP2A1 expression in shINSR cells (Fig. 4). SLCO2A1/OATP2A1 is involved in the transport of $\mathrm{PGE}_{2}$ to the central nervous system at the BBB [51, 52]. The protein expression of SLCO2A1/ OATP2A1 is decreased in the brains of patients with AD compared to healthy controls [53]. Thus, INSRmediated regulation plays a role in the reduction of SLCO2A1/OATP2A1 in the AD brain.

The present proteomic study revealed that protein expression levels of transporters and receptors, which play important roles in the BBB, such as MDR1, BCRP, LRP1, and TFRC, were altered in hCMEC/D3 cells following INSR knockdown (Fig. 4). In a previous study on HFD-fed mice, the protein expression of
Abcbla/mdrla and Tfrc was significantly decreased in brain microvessels by $36.0 \%$ and $23.2 \%$, respectively, and Lrp1 was significantly increased by 1.08-fold [18]. It has also been reported that the protein expression of Abcbla/Mdr1a was decreased by $25.0 \%$ in brain microvessels of a rat model of STZ-induced type 1 diabetes [19]. The present results, showing similar changes in shINSR cells (Fig. 4), suggest that INSR-mediated signaling is involved in the regulation of MDR1, BCRP, LRP1, and TFRC in BCECs in the studies mentioned above. In contrast, Slc2a1/Glut1 and Slc7a5/Lat1 were downregulated in HFD-fed mice [18], whereas the expression of these transporters was not affected in shINSR cells. Therefore, signaling other than INSR is likely to regulate the expression of Slc2a1/Glut1 and Lat1 in BCECs of HFD-fed mice.

Protein expression and efflux function of MDR1 were decreased in shINSR cells (Figs. 4 and 5). This suggests that INSR-mediated signaling plays an important role in maintaining the function of MDR1 at the BBB, and attenuation of INSR-mediated signaling, such as insulin resistance, resulted in attenuation of MDR1 function at the BBB. Indeed, our previous study demonstrated the suppression of Abcbla/mdrla expression and function at the BBB in 2-week HFD-fed mice [18]. The suppression of MDR1 function at the BBB leads to the accumulation of substrate drugs in the brain. It was reported that the brain distribution of vincristine, a substrate of ABCB1/MDR1, was increased approximately twofold in a rat model of STZ-induced type 1 diabetes [19]. BCRP also plays a role in the BBB efflux system and has a synergistic efflux function with $\mathrm{ABCB} 1 / \mathrm{MDR} 1$ against $\mathrm{BBB}$ permeability of substrates [54]. The protein expression of BCRP was also decreased in shINSR as well as MDR1 (Fig. 4). Therefore, INSR-mediated regulation is considered to play an important role in maintaining the efflux function of the $\mathrm{BBB}$, and its attenuation is considered to affect drug distribution in the brain.

TFRC is the protein responsible for iron transport to the brain, and its expression is decreased in shINSR cells (Fig. 4). Transferrin binds to iron and is a ligand of TFRC. The protein expression of transferrin was also significantly decreased to $63.1 \%$ in shINSR cells (Table S1, crude membrane fraction). Since iron is essential for the maintenance of normal brain function [55], decreased TFRC and transferrin in the BBB may affect brain function. In addition, abnormal iron accumulation has been reported in many neurodegenerative diseases $[56,57]$. Therefore, the regulation of TFRC expression by INSR at the BBB is considerable to play a role in the maintenance of brain homeostasis. A similar regulation has been reported in hepatocytes. Hyperinsulinemia induces TFRC 
protein expression in rat liver [58]. Insulin treatment induced TFRC expression and transferrin uptake in HepG2 cells, and hypoxia inducible factor-1 (HIF1 ) is involved in this induction [59]. INSR-mediated signaling activates HIF-1 in human and rat vascular smooth muscle cells [60], and HIF-1 is expressed and functional in BMECs [61]. Therefore, it is a possibility that HIF-1 is involved in INSR-mediated regulation of TFRC at the BBB. In the present proteome data, several HIF-1 regulated proteins, such as platelet endothelial cell adhesion molecule (PECAM1), heme oxygenase 1 (HO-1), and leptin receptor [62-64], were significantly suppressed in shINSR cells (Table S1). HIF-1 is positively involved in ABCB1/MDR1 expression in cancer cells [65]. The PKC/NF-kB pathway was also reported to be involved in the induction of Abcbla/mdrla by insulin in rat BCECs [66]. Therefore, it is possible that INSR-mediated regulation of ABCB1/MDR1 expression involves HIF-1 and/or $\mathrm{PKC} / \mathrm{NF}-\mathrm{kB}$.

A previous study has demonstrated that treatment with insulin increases tight junction integrity in hCMEC/D3 cells [16]. Endothelial-specific INSR knockout mice reportedly exhibit an increase in the brain distribution of fluorescent dextran, mainly in the median eminence and olfactory bulb [25]. Claudin-5 is a key molecule for tight junction formation at the BBB [67], and HFD-fed mice showed a decrease in claudin-5 expression in brain microvessels [18]. Along with the present results presenting claudin- 5 suppression in shINSR cells in Fig. 6, INSR-mediated signaling may contribute to the maintenance of tight junction integrity by regulating claudin- 5 expression. Claudin- 5 was not detected by quantitative proteomics, as its expression level was below the detection limit. Indeed, we have previously reported that the expression of claudin- 5 was lower than ABCG2/BCRP in the plasma membrane fraction of hCMEC/D3 cells, which was also undetectable [15].

In contrast to claudin-5, INSR knockdown induced occludin and claudin-11 in hCMEC/D3 cells. Occludin localizes at the cell-cell contact region of BCECs and is involved in regulating tight junction integrity [68]. Occludin and claudin-5 expression are reportedly suppressed in the brain microvessels of HFD-fed mice [18]. The present result that INSR knockdowninduced occludin expression fails to clarify this suppression. Claudin-11 was expressed in BMECs, and its suppression increased the paracellular permeability of BMECs [69]. The induction of occludin and claudin-11 in shINSR cells might be a compensatory mechanism against claudin- 5 suppression to maintain the integrity of tight junctions. However, in vivo knockdown of claudin-5 did not alter occludin expression in mouse brain microvessels [70]. Furthermore, it should be noted that the present study cultured cells on plastic wells, which are deemed unsuitable conditions for forming tight junctions. Further studies using Transwell cell culture inserts are necessary to analyze the contribution of INSR to tight junction regulation at the BBB.

\section{CONCLUSIONS}

The present study indicates that the suppression of INSR signaling changes the protein expression levels of transporters, tight junctions, and receptors in cultured human BMECs, decreasing expression levels of ABCB1/MDR1, ABCG2/BCRP, SLCO2A1/OATP2A1, claudin-5, and TFRC, while increasing expression levels of occludin, claudin-11, and LRP1. This suggests that the activation of INSR is necessary for expressing the BBB functions, and attenuation of its signal leads to BBB dysfunction. In addition, INSR-knockdown affected the expression levels of proteins related to $A \beta$ production, degradation, and clearance. This altered expression may be associated with the development of $\mathrm{AD}$ and $\mathrm{CAA}$ in insulin signaling-attenuated conditions.

Author Contributions All authors, Nagano H, Ito S, Masuda $\mathrm{T}$, and Ohtsuki S contributed to the study design and manuscript revision. Nagano conducted the experiments and performed data analysis. Nagano $\mathrm{H}$ and Ohtsuki S wrote the manuscript. All authors provided final approval for the submitted manuscript.

Funding This work was supported in part by JPSP KAKENHI (21H02649) and JST CREST (JP171024167).

\section{Declarations}

Conflict of Interest The authors declare that they have no conflicts of interest.

\section{REFERENCES}

1. Abbott NJ, Ronnback L, Hansson E. Astrocyte-endothelial interactions at the blood-brain barrier. Nat Rev Neurosci. 2006;7(1):41-53.

2. Ohtsuki S, Terasaki T. Contribution of carrier-mediated transport systems to the blood-brain barrier as a supporting and protecting interface for the brain; importance for CNS drug discovery and development. Pharm Res. 2007;24(9):1745-58.

3. Ballabh P, Braun A, Nedergaard M. The blood-brain barrier: an overview: structure, regulation, and clinical implications. Neurobiol Dis. 2004;16(1):1-13. 
4. Groothuis DR, Vriesendorp FJ, Kupfer B, Warnke PC, Lapin GD, Kuruvilla A, Vick NA, Mikhael MA, Patlak CS. Quantitative measurements of capillary transport in human brain tumors by computed tomography. Ann Neurol. 1991;30(4):581-8.

5. Lou J, Chofflon M, Juillard C, Donati Y, Mili N, Siegrist CA, Grau GE. Brain microvascular endothelial cells and leukocytes derived from patients with multiple sclerosis exhibit increased adhesion capacity. NeuroReport. 1997;8(3):629-33.

6. van de Haar HJ, Burgmans S, Jansen JF, van Osch MJ, van Buchem MA, Muller M, Hofman PA, Verhey FR, Backes WH. Blood-brain barrier leakage in patients with early alzheimer disease. Radiology. 2016;281 (2):527-35.

7. Montagne A, Nation DA, Pa J, Sweeney MD, Toga AW, Zlokovic BV. Brain imaging of neurovascular dysfunction in Alzheimer's disease. Acta Neuropathol. 2016;131(5):687-707.

8. Ueno M. Elucidation of mechanism of blood-brain barrier damage for prevention and treatment of vascular dementia. Rinsho Shinkeigaku. 2017;57(3):95-109.

9. Baglietto-Vargas D, Shi J, Yaeger DM, Ager R, LaFerla FM. Diabetes and Alzheimer's disease crosstalk. Neurosci Biobehav Rev. 2016;64:272-87.

10. Ott A, Stolk RP, van Harskamp F, Pols HA, Hofman A, Breteler MM. Diabetes mellitus and the risk of dementia: The Rotterdam Study. Neurology. 1999;53(9):1937-42.

11. Matsuzaki T, Sasaki K, Tanizaki Y, Hata J, Fujimi K, Matsui Y, Sekita A, Suzuki SO, Kanba S, Kiyohara Y, Iwaki T. Insulin resistance is associated with the pathology of Alzheimer disease: the Hisayama study. Neurology. 2010;75(9):764-70.

12. Jolivalt CG, Hurford R, Lee CA, Dumaop W, Rockenstein $\mathrm{E}$, Masliah E. Type 1 diabetes exaggerates features of Alzheimer's disease in APP transgenic mice. Exp Neurol. 2010;223(2):422-31

13. American DA. Diagnosis and classification of diabetes mellitus. Diabetes Care. 2013;36(Suppl 1):S67-74.

14. Kellar D, Craft S. Brain insulin resistance in Alzheimer's disease and related disorders: mechanisms and therapeutic approaches. Lancet Neurol. 2020;19(9):758-66.

15. Ohtsuki S, Ikeda C, Uchida Y, Sakamoto Y, Miller F, Glacial F, Decleves X, Scherrmann JM, Couraud PO, Kubo Y, Tachikawa M, Terasaki T. Quantitative targeted absolute proteomic analysis of transporters, receptors and junction proteins for validation of human cerebral microvascular endothelial cell line hCMEC/D3 as a human blood-brain barrier model. Mol Pharm. 2013;10(1):289-96.

16. Ito S, Yanai M, Yamaguchi S, Couraud PO, Ohtsuki S. Regulation of tight-junction integrity by insulin in an in vitro model of human blood-brain barrier. J Pharm Sci. 2017;106(9):2599-605.

17. Kuai Z, Xu Y, Zhao Q, Liu J, Guan S, Qiao Y, Gong X, Nie J, Li P, Liu D, Xing Y, Li H, Sun Z, Wang W, Ning C, Shi Y, Kong W, Shan Y. Effects of insulin on transcriptional response and permeability in an in vitro model of human blood-brain barrier. J Cell Biochem. 2018;119(7):5657-64.

18. Ogata S, Ito S, Masuda T, Ohtsuki S. Changes of blood-brain barrier and brain parenchymal protein expression levels of mice under different insulin-resistance conditions induced by high-fat diet. Pharm Res. 2019;36(10):141.

19. Liu H, Liu X, Jia L, Liu Y, Yang H, Wang G, Xie L. Insulin therapy restores impaired function and expression of P-glycoprotein in blood-brain barrier of experimental diabetes. Biochem Pharmacol. 2008;75(8):1649-58.

20. Meijer RI, Gray SM, Aylor KW, Barrett EJ. Pathways for insulin access to the brain: the role of the microvascular endothelial cell. Am J Physiol Heart Circ Physiol. 2016;311(5):H1132-8.
21. Gray SM, Aylor KW, Barrett EJ. Unravelling the regulation of insulin transport across the brain endothelial cell. Diabetologia. 2017;60(8):1512-21.

22. Boado RJ, Zhang Y, Zhang Y, Pardridge WM. Genetic engineering, expression, and activity of a fusion protein of a human neurotrophin and a molecular Trojan horse for delivery across the human blood-brain barrier. Biotechnol Bioeng. 2007;97(6):1376-86.

23. Boado RJ, Zhang Y, Zhang Y, Wang Y, Pardridge WM. GDNF fusion protein for targeted-drug delivery across the human blood-brain barrier. Biotechnol Bioeng. 2008;100(2):387-96.

24. Boado RJ, Hui EK, Lu JZ, Pardridge WM. Drug targeting of erythropoietin across the primate blood-brain barrier with an IgG molecular Trojan horse. J Pharmacol Exp Ther. 2010;333(3):961-9.

25. Konishi M, Sakaguchi M, Lockhart SM, Cai W, Li ME, Homan EP, Rask-Madsen C, Kahn CR. Endothelial insulin receptors differentially control insulin signaling kinetics in peripheral tissues and brain of mice. Proc Natl Acad Sci U S A. 2017;114(40):E8478-87.

26. Weksler BB, Subileau EA, Perriere N, Charneau P, Holloway K, Leveque M, Tricoire-Leignel H, Nicotra A, Bourdoulous S, Turowski P, Male DK, Roux F, Greenwood J, Romero IA, Couraud PO. Blood-brain barrier-specific properties of a human adult brain endothelial cell line. FASEB J. 2005;19(13):1872-4.

27. Masuda T, Hoshiyama T, Uemura T, Hirayama-Kurogi M, Ogata S, Furukawa A, Couraud PO, Furihata T, Ito S, Ohtsuki S. Large-scale quantitative comparison of plasma transmembrane proteins between two human blood-brain barrier model cell lines, hcmec/d3 and hbmec/cibeta. Mol Pharm. 2019;16(5):2162-71.

28. Masuda T, Tomita M, Ishihama Y. Phase transfer surfactantaided trypsin digestion for membrane proteome analysis. J Proteome Res. 2008;7(2):731-40.

29. Masuda T, Saito N, Tomita M, Ishihama Y. Unbiased quantitation of Escherichia coli membrane proteome using phase transfer surfactants. Mol Cell Proteomics. 2009;8(12):2770-7.

30. Demichev V, Messner CB, Vernardis SI, Lilley KS, Ralser M. DIA-NN: neural networks and interference correction enable deep proteome coverage in high throughput. Nat Methods. 2020;17(1):41-4.

31. Cox J, Hein MY, Luber CA, Paron I, Nagaraj N, Mann M. Accurate proteome-wide label-free quantification by delayed normalization and maximal peptide ratio extraction, termed MaxLFQ. Mol Cell Proteomics. 2014;13(9):2513-26.

32. Kanehisa M, Goto S. KEGG: kyoto encyclopedia of genes and genomes. Nucleic Acids Res. 2000;28(1):27-30.

33. Kohata T, Ito S, Masuda T, Furuta T, Nakada M, Ohtsuki S. Laminin subunit alpha-4 and osteopontin are glioblastomaselective secreted proteins that are increased in the cerebrospinal fluid of glioblastoma patients. J Proteome Res. 2020;19(8):3542-53.

34. Kuno T, Hirayama-Kurogi M, Ito S, Ohtsuki S. Effect of intestinal flora on protein expression of drug-metabolizing enzymes and transporters in the liver and kidney of germ-free and antibiotics-treated mice. Mol Pharm. 2016;13(8):2691-701.

35. Nakamura K, Hirayama-Kurogi M, Ito S, Kuno T, Yoneyama T, Obuchi W, Terasaki T, Ohtsuki S. Large-scale multiplex absolute protein quantification of drug-metabolizing enzymes and transporters in human intestine, liver, and kidney microsomes by SWATH-MS: Comparison with MRM/SRM and HR-MRM/PRM. Proteomics. 2016;16(15-16):2106-17. 
36. Pino LK, Searle BC, Bollinger JG, Nunn B, MacLean B, MacCoss MJ. The Skyline ecosystem: Informatics for quantitative mass spectrometry proteomics. Mass Spectrom Rev. 2020;39(3):229-44.

37. Farris W, Mansourian S, Chang Y, Lindsley L, Eckman EA, Frosch MP, Eckman CB, Tanzi RE, Selkoe DJ, Guenette S. Insulin-degrading enzyme regulates the levels of insulin, amyloid beta-protein, and the beta-amyloid precursor protein intracellular domain in vivo. Proc Natl Acad Sci U S A. 2003;100(7):4162-7.

38. Iwata N, Tsubuki S, Takaki Y, Shirotani K, Lu B, Gerard NP, Gerard C, Hama E, Lee HJ, Saido TC. Metabolic regulation of brain Abeta by neprilysin. Science. 2001;292(5521):1550-2.

39. Storck SE, Meister S, Nahrath J, Meissner JN, Schubert N, Di Spiezio A, Baches S, Vandenbroucke RE, Bouter Y, Prikulis I, Korth C, Weggen S, Heimann A, Schwaninger M, Bayer TA, Pietrzik CU. Endothelial LRP1 transports amyloid-beta(1-42) across the blood-brain barrier. J Clin Invest. 2016;126(1):123-36.

40. Masuda T, Mori A, Ito S, Ohtsuki S. Quantitative and targeted proteomics-based identification and validation of drug efficacy biomarkers. Drug Metab Pharmacokinet. 2021;36:100361.

41. Demeule M, Currie JC, Bertrand Y, Che C, Nguyen T, Regina A, Gabathuler R, Castaigne JP, Beliveau R. Involvement of the low-density lipoprotein receptor-related protein in the transcytosis of the brain delivery vector angiopep-2. J Neurochem. 2008;106(4):1534-44.

42. Fishman JB, Rubin JB, Handrahan JV, Connor JR, Fine RE. Receptor-mediated transcytosis of transferrin across the blood-brain barrier. J Neurosci Res. 1987;18(2):299-304.

43. Wu C, Okar DA, Stoeckman AK, Peng LJ, Herrera AH, Herrera JE, Towle HC, Lange AJ. A potential role for fructose2,6-bisphosphate in the stimulation of hepatic glucokinase gene expression. Endocrinology. 2004;145(2):650-8.

44. Bischof MG, Krssak M, Krebs M, Bernroider E, Stingl H, Waldhausl W, Roden M. Effects of short-term improvement of insulin treatment and glycemia on hepatic glycogen metabolism in type 1 diabetes. Diabetes. 2001;50(2):392-8.

45. Cai Y, Guo H, Fan Z, Zhang X, Wu D, Tang W, Gu T, Wang S, Yin A, Tao L, Ji X, Dong H, Li Y, Xiong L. Glycogenolysis Is crucial for astrocytic glycogen accumulation and brain damage after reperfusion in ischemic stroke. iScience. 2020;23(5):101136.

46. Pflanzner T, Janko MC, Andre-Dohmen B, Reuss S, Weggen S, Roebroek AJ, Kuhlmann CR, Pietrzik CU. LRP1 mediates bidirectional transcytosis of amyloid-beta across the bloodbrain barrier. Neurobiol Aging. 2011;32(12):2323-e1-11.

47. Cirrito JR, Deane R, Fagan AM, Spinner ML, Parsadanian M, Finn MB, Jiang H, Prior JL, Sagare A, Bales KR, Paul SM, Zlokovic BV, Piwnica-Worms D, Holtzman DM. P-glycoprotein deficiency at the blood-brain barrier increases amyloidbeta deposition in an Alzheimer disease mouse model. J Clin Invest. 2005;115(11):3285-90.

48. Storck SE, Hartz AMS, Bernard J, Wolf A, Kachlmeier A, Mahringer A, Weggen S, Pahnke J, Pietrzik CU. The concerted amyloid-beta clearance of LRP1 and ABCB1/P-gp across the blood-brain barrier is linked by PICALM. Brain Behav Immun. 2018;73:21-33.

49. Brenowitz WD, Nelson PT, Besser LM, Heller KB, Kukull WA. Cerebral amyloid angiopathy and its co-occurrence with Alzheimer's disease and other cerebrovascular neuropathologic changes. Neurobiol Aging. 2015;36(10):2702-8.

50. Peila R, Rodriguez BL, Launer LJ, Honolulu-Asia AS. Type 2 diabetes, APOE gene, and the risk for dementia and related pathologies: The Honolulu-Asia Aging Study. Diabetes. 2002;51(4):1256-62.

51. Akanuma S, Uchida Y, Ohtsuki S, Tachikawa M, Terasaki T, Hosoya K. Attenuation of prostaglandin E2 elimination across the mouse blood-brain barrier in lipopolysaccharideinduced inflammation and additive inhibitory effect of cefmetazole. Fluids Barriers CNS. 2011;8:24.

52. Nakamura Y, Nakanishi T, Shimada H, Shimizu J, Aotani R, Maruyama S, Higuchi K, Okura T, Deguchi Y, Tamai I. Prostaglandin transporter OATP2A1/SLCO2A1 is essential for body temperature regulation during fever. J Neurosci. 2018;38(24):5584-95.

53. Choi K, Zhuang H, Crain B, Dore S. Expression and localization of prostaglandin transporter in Alzheimer disease brains and age-matched controls. J Neuroimmunol. 2008;195(1-2):81-7.

54. Kodaira H, Kusuhara H, Ushiki J, Fuse E, Sugiyama Y. Kinetic analysis of the cooperation of P-glycoprotein (P-gp/Abcb1) and breast cancer resistance protein (Bcrp/ Abcg2) in limiting the brain and testis penetration of erlotinib, flavopiridol, and mitoxantrone. J Pharmacol Exp Ther. 2010;333(3):788-96.

55. Munoz P, Humeres A. Iron deficiency on neuronal function. Biometals. 2012;25(4):825-35.

56. Damulina A, Pirpamer L, Soellradl M, Sackl M, Tinauer C, Hofer E, Enzinger C, Gesierich B, Duering M, Ropele S, Schmidt R, Langkammer C. Cross-sectional and longitudinal assessment of brain iron level in Alzheimer disease using 3-T MRI. Radiology. 2020;296(3):619-26.

57. Zecca L, Youdim MB, Riederer P, Connor JR, Crichton RR. Iron, brain ageing and neurodegenerative disorders. Nat Rev Neurosci. 2004;5(11):863-73.

58. Jiang X, Wang H, Shi W, Shen Z, Shen H, Li M. Hyperinsulinemia induces hepatic iron overload by increasing liver TFR1 via the PI3K/IRP2 pathway. J Mol Endocrinol. 2014;53(3):381-92.

59. Biswas S, Tapryal N, Mukherjee R, Kumar R, Mukhopadhyay CK. Insulin promotes iron uptake in human hepatic cell by regulating transferrin receptor- 1 transcription mediated by hypoxia inducible factor- 1 . Biochim Biophys Acta. 2013;1832(2):293-301.

60. Doronzo G, Russo I, Mattiello L, Riganti C, Anfossi G, Trovati $\mathrm{M}$. Insulin activates hypoxia-inducible factor-1alpha in human and rat vascular smooth muscle cells via phosphatidylinositol-3 kinase and mitogen-activated protein kinase pathways: impairment in insulin resistance owing to defects in insulin signalling. Diabetologia. 2006;49(5):1049-63.

61. Yan J, Zhang Z, Shi H. HIF-1 is involved in high glucoseinduced paracellular permeability of brain endothelial cells. Cell Mol Life Sci. 2012;69(1):115-28.

62. Musumeci G, Castorina A, Magro G, Cardile V, Castorina S, Ribatti D. Enhanced expression of CD31/platelet endothelial cell adhesion molecule 1 (PECAM1) correlates with hypoxia inducible factor-1 alpha (HIFlalpha) in human glioblastoma multiforme. Exp Cell Res. 2015;339(2):407-16.

63. Lee PJ, Jiang BH, Chin BY, Iyer NV, Alam J, Semenza GL, Choi AM. Hypoxia-inducible factor-1 mediates transcriptional activation of the heme oxygenase-1 gene in response to hypoxia. J Biol Chem. 1997;272(9):5375-81.

64. Koda M, Sulkowska M, Kanczuga-Koda L, Cascio S, Colucci G, Russo A, Surmacz E, Sulkowski S. Expression of the obesity hormone leptin and its receptor correlates with hypoxiainducible factor-1 alpha in human colorectal cancer. Ann Oncol. 2007;18(Suppl 6):vi116-9. 
65. Doublier S, Belisario DC, Polimeni M, Annaratone L, Riganti C, Allia E, Ghigo D, Bosia A, Sapino A. HIF-1 activation induces doxorubicin resistance in MCF7 3-D spheroids via P-glycoprotein expression: a potential model of the chemoresistance of invasive micropapillary carcinoma of the breast. BMC Cancer. 2012;12:4.

66. Liu H, Yang H, Wang D, Liu Y, Liu X, Li Y, Xie L, Wang $\mathrm{G}$. Insulin regulates $\mathrm{P}$-glycoprotein in rat brain microvessel endothelial cells via an insulin receptor-mediated $\mathrm{PKC} / \mathrm{NF}-$ kappaB pathway but not a PI3K/Akt pathway. Eur J Pharmacol. 2009;602(2-3):277-82.

67. Nitta T, Hata M, Gotoh S, Seo Y, Sasaki H, Hashimoto N, Furuse M, Tsukita S. Size-selective loosening of the bloodbrain barrier in claudin-5-deficient mice. J Cell Biol. 2003;161(3):653-60.

68. Haseloff RF, Dithmer S, Winkler L, Wolburg H, Blasig IE. Transmembrane proteins of the tight junctions at the bloodbrain barrier: structural and functional aspects. Semin Cell Dev Biol. 2015;38:16-25.
69. Uchida Y, Sumiya T, Tachikawa M, Yamakawa T, Murata S, Yagi Y, Sato K, Stephan A, Ito K, Ohtsuki S, Couraud PO, Suzuki T, Terasaki T. Involvement of claudin-11 in disruption of blood-brain, -spinal cord, and -arachnoid barriers in multiple sclerosis. Mol Neurobiol. 2019;56(3):2039-56.

70. Keaney J, Walsh DM, O'Malley T, Hudson N, Crosbie DE, Loftus T, Sheehan F, McDaid J, Humphries MM, Callanan JJ, Brett FM, Farrell MA, Humphries P, Campbell M. Autoregulated paracellular clearance of amyloid-beta across the bloodbrain barrier. Sci Adv. 2015;1(8):e1500472.

Publisher's Note Springer Nature remains neutral with regard to jurisdictional claims in published maps and institutional affiliations. 